\title{
Fighting the Challenges of Non Communicable Diseases (Ncds)
}

\author{
Nirav Soni* \\ Department of Quality Assurance, A-One Pharmacy College, India
}

Submission: April 22, 2017; Published: June 01, 2017

*Corresponding author: Nirav Soni, Department of Quality Assurance, A-One Pharmacy College, India, Tel: +91-9033002567;

Email: nirav_sonic@yahoo.com

Keywords: Non-communicable diseases; Sexual transmitted disease; Cardiovascular diseases; Heart diseases; Chronic respiratory diseases; Hypertension; World health organization; Public health centre; Global monitoring framework; Chronic obstructive pulmonary disease; National mental health program; Female welfare assistant; Community health workers; Neuro-development disorders; Behavior change communication=

Abbreviations: NCDs: Non-Communicable Diseases; STD: Sexual Transmitted Disease; CVD: Cardiovascular Diseases; HD: Heart Diseases; CRD: Chronic Respiratory Diseases; HTN: Hypertension; WHO: World Health Organization; PHC: Public Health Centre; GMF: Global Monitoring Framework; COPD: Chronic Obstructive Pulmonary Disease; NMHP: National Mental Health Program; FWAs: Female Welfare Assistant; CHWs: Community Health Workers; NDDs: Neuro-Development Disorders; BCC: Behavior Change Communication

\section{Introduction}

This review investigates social determinants of national health particularly looking at non-communicable diseases (NCDs) and argues that structural interventions in the economy and society are necessary to reduce the prevalence of NCDs [1]. Sociologists study health demographics because patterns of health change across classes, cultures, genders and countries. Disease does not have solely biological causes, but it is also identified by factors such as the socio-cultural environment, economic status, living and working conditions and government legislation. It is a medical condition or chronic diseases which not passed from person to person so that's why it is called noninfectious and non transferable [2]. Chronic NCDs are assuming increasing significance all among the adult people in both developed and developing countries such as CVS and cancer are at present the leading causing the mortality. They are renowned only by their non-infectious cause, not essentially by their duration. Some chronic diseases of long duration, such as HIV/ AIDS, are caused by STD (Sexual Transmitted Disease). Chronic diseases required critical care management as do all diseases that are slow to develop, long duration and progress slowly.

Firstly, let us consider of the prevalence and environmental causes of NCDs. It is defined chronic conditions that do not result from an acute infectious process. There are four major categories of NCD such as Diabetes, Cardiovascular Diseases (CVD) or Heart diseases (HD), Chronic Respiratory Diseases (CRD) and another major is cancer (Carcinoma, Sarcoma and leukemia) are leading to cause of death in the world. Other NCDs classified blindness and other metabolic and degenerative diseases, nervous and renal disease and osteoporosis $[3,4]$.

In the world, suffering 5.8 million people hypertension (HTN), 2.6 million diabetes, 2.5 million obesity and hypercholesterolemia. The total number of deaths worldwide from NCDs each year 36 million, representing the 63\% of all annual deaths, according to World Health Organization (WHO), as population will age, annual NCD deaths are projected to rise substantially, to 52 billion in 2030. There are various characteristics of NCDs including complex etiology (causes), multiple risk factors, long latency period, non-contagious origin (non-communicable), prolonged course of illness and functional impairment or disability [5,6].

The main objective of NCD is to know about the national health, understand and relevance of this area and developed Public Health Centre (PHC) and raise the scope of itself. Collect the data and design the particular therapy or treatments of NCDs. Determination and Utilization of government funds and non-government organizations for NCDs [7]. 
We discussed about the scope of NCD is the action plan provides a road map and a menu of policy options for all member states and other stakeholders, to take coordinated and reliable action, at all levels, local to global, to attain the nine voluntary global targets, counting that of a $25 \%$ relative reduction in premature mortality from cardiovascular diseases, cancer, diabetes or chronic respiratory diseases by 2020 [8]. Global

\section{Mortality and morbidity}

Unconditional probability of dying between ages 30 and 70 years from CVS, cancer, Diabetes and COPD (Chronic Obstructive Pulmonary Disease).

\section{Risk factors}

a. Non-modifiable like Age, Gender, Family History, Ethnicity, Prior stroke or heart attack and

b. Modifiable including tobacco use, junk food/unhealthy diet, poor nutrition, obesity, physical inactivity, excess use of alcohol, raised blood sugar and bad cholesterol (LDL), decreased vegetable and fruit intake, cancer associated infections, environmental risk factors and lastly stress.

\section{National system response}

Marketing to children access to palliative care, Policies to limit saturated fats and virtually eliminate trans-fats. Moreover; about Myths of NCDs, It is much less common than infectious diseases such as T.B, Malaria, HIV and diarrhea and unrelated to infectious diseases. It is too expensive and complex to treat and takes focus away from infectious diseases. The effects of NCDs are the burden of chronic NCDs including mental health conditions is felt in workplaces around the world, notably due to elevated levels of absenteeism, or absence from work because of illness and present eeism, or productivity lost from staff coming to work and performing below normal standards due to poor health and on four shared behavioral risk factors- tobacco use, unhealthy diet, physical inactivity and harmful use of alcohol. It recognizes that the conditions in which people live and work and their lifestyles influence their health and quality of life $[9,10]$.

In addition, there is a list of innovative steps which we should take in the near future for kill or prevention of NCDs states and developed "TELEMEDINES" and vitamin supplements, developed vaccination and drug therapy and counseling, monitoring, protection, offer help to quite, warning, raise taxes on tobacco products and enforce anti-tobacco law, arrangement of "national programs" with survey like national cancer control program, National Mental Health Program (NMHP), National Diabetes Control Program (NDCP) etc. [11-14]. usage of proper drug medication or stop the OTC product, mandatory recreational space for physical activities in residential areas, providing arsenic free water to arsenic affected area, raising awareness about the link between children's obsession with electronic gadgets and child obesity, provision of government fund for NCD research, redesign curriculum for adolescent NCD education, scale up NCD detection systems, mobile, universal tests for screening breast cancer, Female Welfare Assistant (FWAs) to disseminate NCDs related information, specific NCD programs for rural-urban area, reduce salt use at the cooking stage and awareness on product's contents in particular salt proportions, mandatory contents description on processed foods, more care of antenatal and neonatal, campaign on Hepatitis B and invest multi-drug resistance $\mathrm{TB}$, raise awareness of Community Health Workers (CHWs) on NCDs, affordability and availability of cervical and breast cancer treatments, awareness on neuroDevelopment Disorders (NDDs) in districts and regions, impact of industrialization and unplanned urbanization on NCDs, programs for coastal belt people being affected by salinity (e.g. hypertension) and women in danger of pregnancy complications (e.g. eclampsia), prepare comprehensive strategies for preventing and treating NCDs [15-17].

The problem of NCDscan be viewed either from the perspective of the individual (who does not live a healthy lifestyle), or from the society (one that does not offer a satisfactory means of living a healthy lifestyle). The environmental causes mentioned above indicate that there are factors outside of the locus of control of the individual which contribute to NCD, and lead one to task the community and government with NCD prevention. Another perspective is that addiction to smoking, eating fatty foods or drinking alcohol could lead to NCD contraction [18].

\section{What are the important elements of national NCD prevention policies?}

a) There should be a focus on building capacity in primary health care (PHC) to deal with NCDs. A focus on PHC is significant in order to an object the causes of NCD and prevent cases from progressing (until secondary health care treatment is needed). A PHC model of intervention focuses on strengthening the district health care system, delivering services through community-based and to achieving desired public good health. As an example, physical activity can be promoted through ensuring that physical environments are safe and through community-led initiatives to promote exercise

b) To NCD prevention policies is enforcing legislation. Protecting people from unnecessary exposure to harmful risk factors is crucial, such as laws against smoking in public places, bans or restrictions on advertising for cigarettes and alcohol and restrictions on unhealthy food and sugary beverages.

c) Behaviors can be distorted through education and awareness for the public, and the continuing education of medical personnel, about how to manage one's lifestyle in a healthy way throughout these intervention strategies, monitoring is essential.

Overall, this essay has examined the social and economic 
causes of NCDs, and has recommended strategies for NCD prevention and scaling up of NCD health promotion activities through behavior change communication (BCC), increasing capacity of service providers to care for NCDs in rural health centers, and, more government financial support for researchers in the field of NCDs was identified as three major challenges. An NCD 'BEST BUYS' (according to WHO) are interventions with compelling evidence for cost-effectiveness, cheap, and feasible to implement in all health systems and various resource levels, including in low resource settings, and culturally appropriate in all countries [19]. NCDs will be the predominant global public health challenge of the 21st century. It is unique in that they are caused primarily by unhealthy lifestyle decisions and the epidemic scale of NCDs wants a macro-level response from the communities and governments. This reaction should be multisectoral and attention towards NCD prevention is required in health policies and practices. The modern need to linger healthy within an urban environment requires creative and informed solutions. Prevention of premature deaths due to NCDs and lessening of related health care costs will be the main goals of health policy. Modifying the detection and treatment of NCDs and preventing complications and catastrophic events will be the major goals of clinical medicine [20].

A multilevel approach that integrates policy actions, rules and regulations, health education, and well-organized health systems to attain these goals will be the mission of public health. All countries can benefit by sharing experience and pooling expertise for the prevention and control of NCDs. As a final thought, the fight against NCDs may leave one to wonder what type of death is 'desired', or it will be common once we have 'won the battle' against NCDs. Death by 'old age', a frequent response, is not a type of death in itself but represents a death due to frailty as opposed to major exogenous factors [21].

\section{References}

1. Alwan A, Maclean DR (2009) A review of non-communicable disease in low- and middle-income countries. Int Health 1(1): 3-9.

2. Low WY, Lee YK, Samy AL (2015) Non-communicable diseases in the Asia-Pacific region: Prevalence, risk factors and community-based prevention. Int J Occup Med Environ Health 28(1): 20-26.

3. http://www.who.int/nmh/global_monitoring_framework/en/

4. Mark RC, Michael B, Karen E, Pooja L, Victor F (2016) The weaker sex? Vulnerable men and women's resilience to socio-economic disadvantage. SSM- Population Health 2: 512-524.

5. Jacka FN, Sacks G, Berk M, Allender S (2014) Food policies for physical and mental health. BMC Psychiatry 14: 132.
6. Magnusson RS, Patterson D (2014) The role of law and governance reform in the global response to non-communicable diseases. Global Health 10: 44 .

7. Hunter DJ, Reddy KS (2013) Noncommunicable Diseases. N Engl J Med 369(14): 1336-1343.

8. Lee S, Lane P, Daniel W, Mikell G, Michael AT, et al. (2016) Fostering Global Citizenship in Higher Education. Public Health and Welfare: Concepts, Methodologies, Tools, and Applications. 826-847.

9. Adami HO, Hernán MA (2015) Learning how to improve healthcare delivery: the Swedish Quality Registers. J Intern Med 277(1): 87-89.

10. Al Turki YA (2015) Blood Pressure Status during Consultation: A Primary Care Study. High Blood Press Cardiovasc Prev 22(1): 79-82.

11. Frenk J (2015) Leading the way towards universal health coverage: a call to action. Lancet 385(9975): 1352-1358.

12.https://www.cdc.gov/vitalsigns/pdf/2010-08-vitalsigns.pdf

13. Chapman S (2007) Public health advocacy and tobacco control: making smoking history. Blackwell Publishing, Oxford, USA.

14. Coulson N, Goldstein S, Ntuli A (1998) Promoting health in South Africa: an action manual. Heinemann, Sandton, South Africa.

15. Fisher GL, Harrison TC (2009) Models of addiction. In Substance abuse: information for school counselors, social workers, therapists, and counselors. ( $4^{\text {th }}$ edn), Pearson, Boston, USA, pp. 35-49.

16. Goedecke JH, Jennings CL, Lambert EV (2006) Obesity in South Africa. In: Steyn K, Fourie J, Temple N (Eds.), Chronic diseases of lifestyle in South Africa since 1995-2005. (Technical report). South African Medical Research Council, Cape Town, South Africa, pp. 65-79.

17. Maring EF, Braun B (2006) Drug, alcohol and tobacco use in rural, low-income families: an ecological risk and resilience perspective. Journal of Rural Community Psychology.

18. Meyers NED (2008) The changing environment and disease patterns. In: Environmental threats to healthy aging: with a closer look at Alzheimer's and Parkinson's diseases. Physicians for Social Responsibility and Science and Environmental Health Network, Boston, USA, pp. 1737.

19. Moore S, Aiken D, Chapman S (2008) Sociology AS for AQA ( $3^{\text {rd }}$ edn), Collins, London, England.

20. Puska P (2002) Successful prevention of non-communicable diseases: 25 year experiences with North Karelia Project in Finland. Public Health Medicine 4(1): 5-7.

21. Schaay N, Sanders D, Kruger V (2011) Overview of health sector reforms in South Africa. DFID Human Development Resource Centre, London, England. 
Your next submission with Juniper Publishers will reach you the below assets

- Quality Editorial service

- Swift Peer Review

- Reprints availability

- E-prints Service

- Manuscript Podcast for convenient understanding

- Global attainment for your research

- Manuscript accessibility in different formats ( Pdf, E-pub, Full Text, Audio)

- Unceasing customer service

Track the below URL for one-step submission https://juniperpublishers.com/online-submission.php 